\title{
SM Otolaryngology Numerical Survey of the Different Shapes of Human Nose
}

\author{
Abraham Tamir ${ }^{*}$ \\ Chemical Engineering Department, Ben-Gurion University of the Negev, Israel
}

\begin{abstract}
Article Information
Received date: Nov 07, 2016

Accepted date: Jan 10, 2017

Published date: Jan 18, 2017

*Corresponding author
\end{abstract}

Abraham Tamir, Chemical Engineering Department, Ben-Gurion University of the Negev, Israel, Tel: +972 8-646-1600; Email: atamir4@012.net.il

Distributed under Creative Commons CC-BY 4.0

Article DOI 10.36876/smotol.1005

\section{Abstract}

The major aim of this article is to report experimental results about the numerical quantities of the different shapes of human nose as well as to classify them into defined shape groups. To the best of the author knowledge this approach has never been applied. The results are based on 1793 pictures of noses of which 403 are artworks, 498 are photographs taken by the author in Europe - Holland, Belgium and France - while visiting these places, 801 were photographed in Israel and 91 are not clear where exactly photographed. 1081 were photographs of men and 712 of women. The author has succeeded to classify all the noses into 14 groups demonstrated in Figure 2 where for each nose shape it was possible to find also an artistic demonstration. The detailed results for the number of noses versus their shape and sources: artworks and photographing places Europe and Israel - are reported in Table 1. The most widespread nose is shape 1, the fleshy nose in Figure 2, $24.2 \%$, where the less widespread nose is shape 4 , turned-up nose, $0.45 \%$. It should be emphasized also that shape 14 photographed in Israel is extremely unique and the only one existing among the 1793 noses that were considered. In addition to the numerical results the following subjects are elaborated with respect to human's nose: its anatomy, its different shapes as well as their relation to human's character and facial attractiveness. And finally it is important to mention the development of electronic/artificial noses as systems for the automated detection and classification of odors, vapors, and gases.

\section{Introduction}

\section{Nose anatomy and functions}

The human nose is an amazingly complex instrument both in form and function where the inside of it is not just straight hollow tubes, but are shaped specifically to regulate its performance. It consists of skin, bone, cartilage, blood vessels, and nerves. It houses our sense of smell, takes an important part in breathing, and sits there in the middle of the face where no one can miss it. It is the organ responsible for the sense of smell. The cavity of the nose is lined with mucous membranes that have smell receptors connected to the olfactory nerve. The smells themselves consist of vapors of various substances. The smell receptors interact with the molecules of these vapors and transmit the sensations to the brain.

Anatomically the nose can be divided into two parts. The external part that sticks out from the face and houses the nostrils that admit air for respiration to enter our body in conjunction with the mouth. The internal part of the nose contains the nasal septum, which is a wall that sits in the middle of the nasal cavity and separates the two sides of the nose. It is made of thin cartilage and bone and is covered by mucous membrane. You can feel the front end of it behind the skin between the nostrils. The top edge is felt by running your finger along the bridge of the middle third of the nose. Each nasal cavity or passage is like a tunnel, which is $6-7 \mathrm{~cm}$ long, running above the roof of the mouth. Along the side wall of each passage are the turbinate. These are sausage like swellings, which can change in size, for example they swell with a cold. Finally the pre-maxilla it is a bone on either side of the middle line between the nose and mouth, forming the anterior part of each half of the upper jawbone. In man the pre maxilla become united and form the incisor part of the maxillary bone.

The nose contains shelf-like structures called turbinate [1], which help to trap particles entering the nasal passages. Material deposited in the nose is transported to the back of the throat. In addition, cold viruses are carried to the back of the throat where they are deposited in the area of the adenoid. The adenoid is a lymph gland structure that contains cells to which the cold viruses attach. Hairs existing inside the nose prevent large particles from entering the lungs. In other words, cleaning the air by removing of foreign bodies is a fundamental function of the nose. Additional function of the nose in addition to smell and cleaning is controlling the temperature of the entering air by warming and humidifying it before reaching the lungs. Sneezing is usually caused by foreign particles irritating the nasal mucosa. On the other hand, sneezing is a means of transmitting infections. Another important function of the nose is the talent to distinguish odors by a clever combinatorial process. When an odor excites a neuron in the nose, the signal travels along the nerve cell's axon and is transferred to the neurons in the olfactory bulb. This structure, located in the very front of the brain, is the clearinghouse for the sense of smell. And finally smell has also a possible role in sexual function. In other words, though personality and looks definitely 


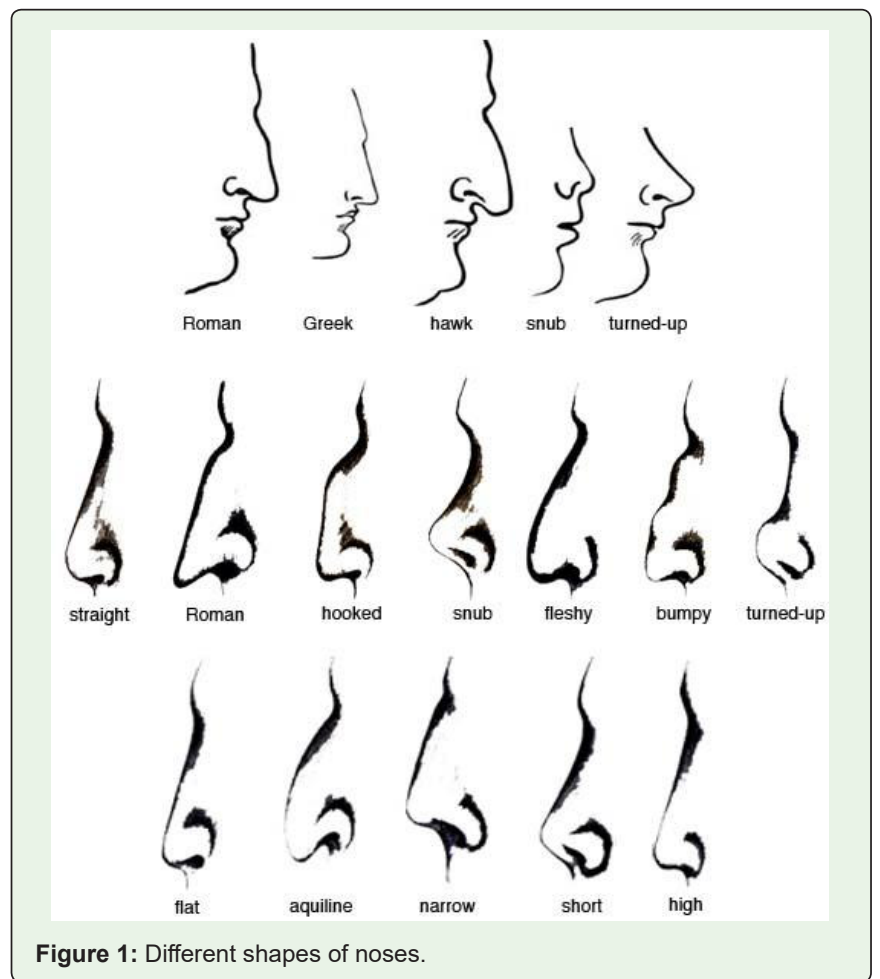

play a part in initial attraction, smell may play a larger role than we suspect. A summary of the functions of the nose is as follows: airway, temperature control, humidification, air cleaning such as removing foreign bodies in the air, air entry for olfactory sense and a possible role in sexual function. The word "nose" [2] derives from the Latin nasus, which referred to the human nose or animal snout. The term is non-specific, and encompasses concepts including the external structure of the human face, the olfactory organ, part of the airway, and part of the immune system. The Chinese [3] consider the nose to be a gauge of wealth and importance. It is also a measure of person's vitality and sexual powers. It is generally agreed that the nose tells us every-thing about our fellow human being's intellect, knowledge and ability to love. It is also important as a bridge between the eyes and mouth. To conclude this chapter it is important to mention new developments in the area of noses [4], namely the electronic/artificial nose as systems for the automated detection and classification of odors, vapors, and gases. An electronic nose is generally composed of a chemical sensing system and a pattern recognition system. Such noses may be applicable for environmental monitoring, for medicine and for the food industry. It is interesting to mention that the prototype presented in [4] has several advantages for real-world applications including compactness, portability, real-time analysis and automation. The major objective of this article is to report the results of a numerical survey performed by the author in Israel and Europe (Brussels-Belgium, Amsterdam-Holland and Paris-France) with regard to the numerical quantities of the different shapes of human's nose. It should be emphasized that such a numerical survey has never been performed. The data were obtained from the Internet, art books and most important by photographing about 2000 noses.

\section{Shapes of Human Noses}

The nose, as with all human features vary greatly in shape or form, both between different nationalities as well as between individuals. Anatomically the shape of the nose is determined by the ethmoid bone and the nasal septum. The ethmoid bone [5] is a bone in the skull that separates the nasal cavity from the brain. It is exceedingly light and spongy, and cubical in shape. It is situated at the anterior part of the base of the cranium, between the two orbits, at the roof of the nose, and contributes to each of these cavities. It should also be noted that the form of the nose could also be related to the underlying structure. For example the "turned up" nose in Figure 1 is formed by poor septal cartilage support and often seen after nasal trauma, or the "snub nose" suggests poor formation of the rhinion. However, despite of the fact that the shape of the nose is determined by the ethmoid bone and the nasal septum, thousands of people undergo surgery of the nose for changing its shape. Nasal surgery may be performed for cosmetic purposes, or a combination procedure to improve both form and function. It also may alleviate or cure nasal breathing problems, correct deformities from birth or injury, or support an aging drooping nose. Rhinoplasty is the surgery undertaken on the nose for a variety of reasons such as functional and aesthetic. Functional reasons include surgery to remove a blockage, correct a deformity or improve breathing. Surgery undertaken for aesthetic reasons tends to improve the shape of the nose. According to [2,3,6] human character may be determined qualitatively by head, nose, eyes, ears, chin and mouth shapes, namely by physiognomy or 'face reading'. Physiognomy is the ancient art of face reading, thought to have originated in China more than 2000 years ago. There is an almost endless variety of shapes of noses and these different shapes very truthfully tell the character of the individual, but as previously stated, one should not fully depend upon the shape of one feature alone. The faculties in the other features of the face must also correspond to a certain extent, at least, with those expressed in the nose if a truthful rendering of the character of the individual is sought. In addition, the more we experience in life, the better we get at reading faces and relating them to personality types and disorders. In conclusion the face is a rich source of information about human behavior and is one of the many tools used by psychic readers. Human noses can take many different shapes as demonstrated in Figure 1. The five noses on the top were reported in [5] according to which the classification is as follows:

1) The Roman or Aquiline nose, which is rather convex, but undulating as its name aquiline imports.

2) The Greek or Straight nose, which is perfectly straight.

3) The Hawk nose, which is very convex, and preserves its convexity like a bow. It is thin and sharp.

4) The Snub nose.

5) The Turn-up or Celestial nose, with a continuous concavity from the eyes to the tip.

The book "Face Reading" [3] provides 12 shapes of noses demonstrated in Figure 1 that correspond also to human's character and described in the following. It should be noted that the determination of the character versus nose shape was based on surveys according to which the character of people was explored versus their nose shape. However, it should be emphasized that the results don't describe by $100 \%$ human character and one should always encounter an exceptional. This is in contrast to scientific laws that describe our universe by $100 \%$ otherwise they should be modified as done by 
scientists. An additional references applying nose shape to character are the books "Face Facts" [7] and "The Naked Face" [8]. It should also be noted that in all $[3,7,8]$ characters are also reported versus mouth and lips, forehead, chin, eyes, teeth, cheeks and ears where in [6] human's character is also deduced from nostrils shape. Since we deal with noses whereas the results of the survey reported in [3] are very interesting, applicable and shed light on human's character versus nose shape, they are elaborated in the following.

1) The Straight nose presents a pleasant appearance and also combines clear thinking, tolerance and trustworthiness with unyielding tenacity. Such people are also likely to be great experts on the subject of art and beauty. Men of this nose type are often found in the media, at the head of a company or in artistic occupation. Women are able to make a career for themselves as personal assistants or gliding along the catwalk as a model.

2) The Roman nose is long and has a downward-sloping tip. It symbolizes courage, ability to make decisions and think clearly. People with this kind of nose are very ambitious, delight in every kind of challenge and can achieve great prosperity in middle age.

3) The Hooked nose presents people who are hungry for success. Women with this type of nose may develop outstanding educational abilities as well as commercial instinct.

4) The Snub nose is a small nose sloping upwards at the tip, so that the nostrils are visible. People with this nose frequently lack spiritual and physical maturity. They appear to know everybody and everything, but they are so carefree that they get into all kind of trouble.

5) People with Fleshy nose - the majority of who are men - are generous, emotional and sensitive, but also enough sensible not to get involved in speculation. In their private life they tend to help others and by and large their life will be positive. Women with this kind of nose may develop great skill in the sphere of home economics, for example in hotel management.

6) A Bumpy nose symbolises an outwardly strong and stubborn character but this is only for show. On the other hand such people can be very generous.

7) Turned-up nose looks similar to that of snub nose, but the edge is plumb and round. This nose symbolises practical thinking, balance and reliability.

8) Flat nose indicates a skilled person, entertaining and fundamentally pessimistic in outlook.

9) Aquiline nose symbolizes a cool tactician person as well as business-minded, aggressive and has considerable stamina.

10) Narrow nose symbolizes self-confident, inclined to stubbornness, vulnerable and interested in spiritual things.

11) Short nose indicates little self-confidence, willing to keep opinions open, liberal and jealous.

12) High nose symbolizes artistic understanding, restless, tendency to be alone as well as being vain.

Talking about nose shapes and its correspondence to human's character it is important to emphasize the fact that nose shape is also strongly related to facial aesthetics. Thus, the reshaping of one's nose is intended to create a more attractive nasal shape and thus improving aesthetics of the front and profile facial sides. Like the nose, although not as well appreciated, the position and form of the facial chin helps to form an impression on one's character as well as his aesthetics. Thus, balancing one's face through chin implant surgery can reverse this image in an immediate and gratifying way.

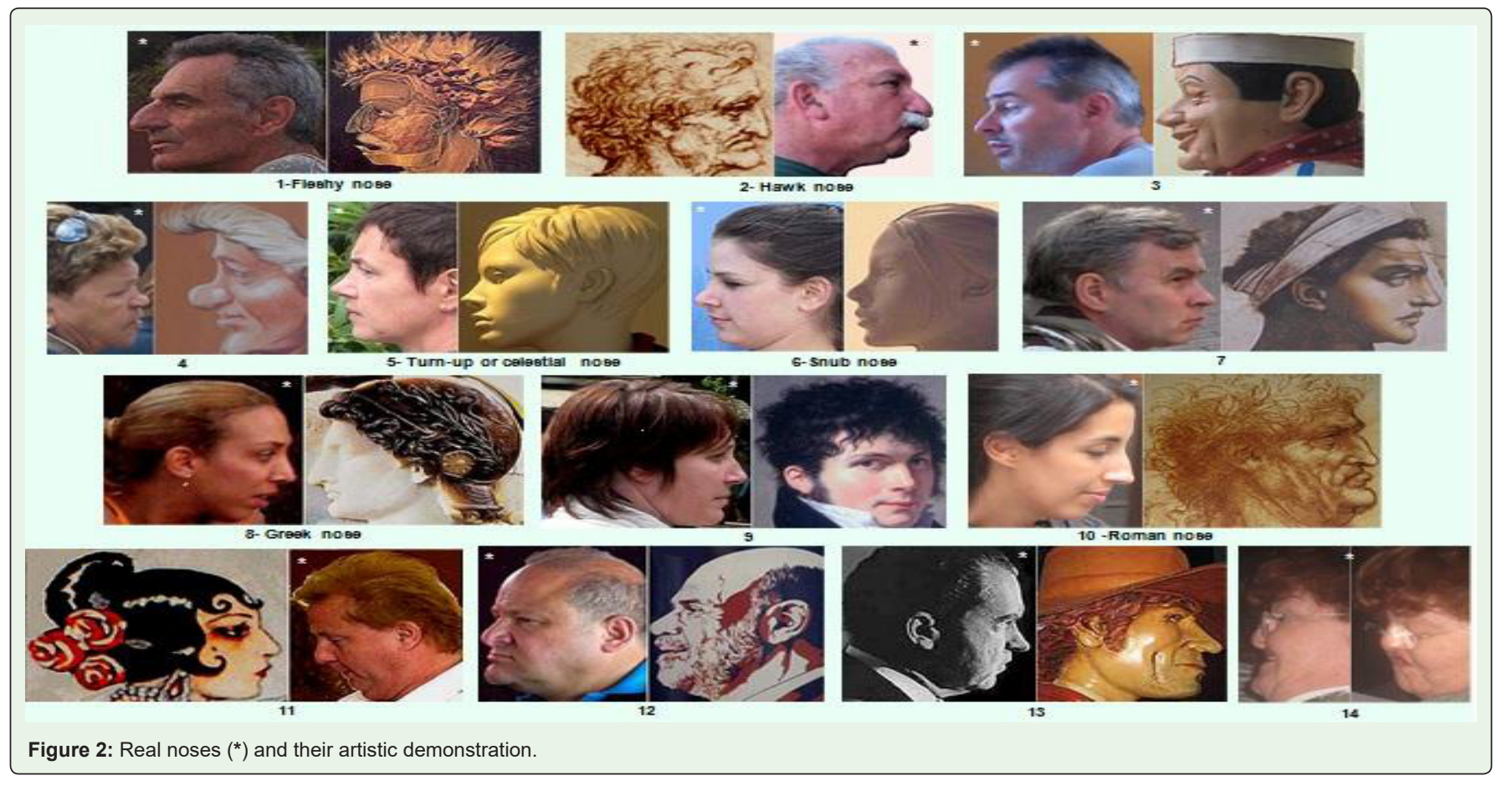

Citation: Tamir A. Numerical Survey of the Different Shapes of Human Nose. SM Otolaryngol. 2017; 1(1): 1005. https://dx.doi.org/10.36876/smotol.1005 
To conclude this part the following remarks are made: 1) Comparison of the noses shape in Figure 1 taken from [5], the top five, and those taken from [3], the twelve below the top five, indicate that the artistic demonstration of the Roman and the turned-up shapes are quite different which create a confusion with regard to what is the real shape. 2) [6] provides artistic demonstrations of eight shapes of noses part of which appear in Figure 2 while the Roman, the hawk, the fleshy and the bumpy are not mentioned at all.

In addition, front views photographs of faces are provided to describe some shapes of noses such as hawk, long, dragon and ewe. However they are not clear at all because not presented by a profile photograph

And finally the following remark should be made $[3,7,8]$ indicate a detailed relationship between nose shape and human character as detailed above according to [3]. However, no information is provided to how this relationship was obtained. Moreover, these references don't contain any additional references wherefrom all the reported information was taken.

Experimental Results of the Different Shapes of Human Nose and Major Conclusions

Two sources were applied to obtain noses of different shapes. The first one is artworks of human face profile found in different artwork books. The second and the major source are pictures of real noses photographed in Israel and in the following countries in Europe where the author visited: Holland, Belgium and France. It should be emphasized that a strict attention has been paid to photograph profile pictures that will yield the exact nose shape.
The author has succeeded to classify all the noses into 14 groups demonstrated in Figure 2 where for each nose shape it was possible to find an artistic demonstration. Shape 14 photographed in Israel is extremely unique and the only one existing among all the noses that were considered. For this shape it was also impossible to find an artistic demonstration. In few cases the difference in the nose shape is small, for example shapes 5 and 6 in Figure 2. However, the edge of shape 5 is sharp where that in shape 6 is lightly rounded. It should be noted that in large-scale pictures, applied in the present research, the small differences become larger and more distinct. And finally when it was possible to compare the photographed nose shape with that in Figure 1, the nose was also presented by a name.

The experimental results for the number of noses versus their shape and source, namely, artworks and the photographing places Europe and Israel - are summarized in Table 1. The total number of noses considered was 1793 of which 1081 were of men and 712 of women. The table includes different shapes of the human nose where to the best of the author knowledge such a numerical approach has never been applied. In addition, of the 1793 pictures, 403 are artworks, 498 are photographs taken by the author in Europe - Holland, Belgium and France - while visiting these places, 801 were photographed in Israel and 91 are not clear where exactly photographed.

The detailed results for the number of noses versus their shape - $i=1,2 \ldots 13$ - and sources: artworks and photographing places are reported in Table 1. In the table it is also reported in details how exactly to consider the results and what precisely each number describes. A distinction was made in the detailed results between men, women and men + women.

Description of Table 1 is distributed in the following 5 Parts.

Table 1: Experimental results for the number of noses versus their sources: artwork and photographing places-Europe and Isrel.

Part 1 of Table 1.

\begin{tabular}{|c|c|c|c|c|c|c|}
\hline \multirow{2}{*}{$\begin{array}{c}\text { Nose shape number i in Figure } 2 \\
\text { Men }\end{array}$} & \multicolumn{3}{|c|}{$\begin{array}{l}\text { Number of noses of a certain nose shape i obtained } \\
\text { from artworks }=t_{k, i}=t_{1, i}\end{array}$} & \multicolumn{3}{|c|}{$\begin{array}{c}\text { Number of noses of a certain shape } i \text { obtained } \\
\text { by pictures taken in Europe }=t_{k, i}=t_{2, i^{\circ}}\end{array}$} \\
\hline & $15.5 \%=X_{1}$ & $46=t_{1,1}$ & $\alpha_{1}=14.3 \%$ & $18.2 \%$ & $50=t_{2,1}$ & $\alpha_{2}=15.5 \%$ \\
\hline $\mathrm{i}=1$ women & $8.4 \%=y_{1}$ & $9=t_{1,1}$ & $\beta_{1}=8.0 \%$ & $7.6 \%$ & $17=t_{2,1}$ & $\beta_{2}=15.2 \%$ \\
\hline men + women & $13.6 \%=Z_{1}$ & $55=t_{1,1}$ & $\gamma_{1}=2.7 \%$ & $13.5 \%$ & $67=t_{2,1}$ & $\gamma_{2}=15.4 \%$ \\
\hline Men & $12.2 \%$ & 36 & $46.2 \%$ & $0.7 \%$ & 2 & $2.6 \%$ \\
\hline $\mathrm{i}=2$ women & $1.9 \%$ & 2 & $22.2 \%$ & $0 \%$ & 0 & $0 \%$ \\
\hline men + women & $9.4 \%$ & 38 & $43.7 \%$ & $0.4 \%$ & 2 & $2.3 \%$ \\
\hline Men & $7.1 \%$ & 21 & $20.0 \%$ & $11.6 \%$ & 32 & $30.4 \%$ \\
\hline $\mathrm{i}=3$ women & $4.7 \%$ & 5 & $7.9 \%$ & $6.7 \%$ & 15 & $23.8 \%$ \\
\hline men + women & $6.5 \%$ & 26 & $15.5 \%$ & $9.4 \%$ & 47 & $28.0 \%$ \\
\hline Men & $1 \%$ & 3 & $50.0 \%$ & $0.7 \%$ & 2 & $33.3 \%$ \\
\hline $\mathrm{i}=4$ women & $0 \%$ & 0 & $0 \%$ & $0.4 \%$ & 1 & $50 \%$ \\
\hline men + women & $0.7 \%$ & 3 & $37.5 \%$ & $0.6 \%$ & 3 & $37.5 \%$ \\
\hline Men & $8.1 \%$ & 24 & $30.8 \%$ & $14.2 \%$ & 39 & $50 \%$ \\
\hline $\mathrm{i}=5$ women & $29.9 \%$ & 32 & $20.8 \%$ & $31.8 \%$ & 71 & $46.1 \%$ \\
\hline men + women & $13.9 \%$ & 56 & $24.1 \%$ & $22.1 \%$ & 110 & $47.4 \%$ \\
\hline Men & $1.4 \%$ & 4 & $11.8 \%$ & $6.5 \%$ & 18 & $52.9 \%$ \\
\hline $\mathrm{i}=6$ women & $9.3 \%$ & 10 & $20 \%$ & $6.3 \%$ & 14 & $28 \%$ \\
\hline men + women & $3.5 \%$ & 14 & $16.7 \%$ & $6.4 \%$ & 32 & $38.1 \%$ \\
\hline
\end{tabular}




\begin{tabular}{|c|c|c|c|c|c|c|}
\hline Men & $18.9 \%=X_{7}$ & $56=t_{1,7}$ & $33.6 \%$ & $17.8 \%$ & $49=t_{2,7}$ & $29.3 \%$ \\
\hline $\mathrm{i}=7$ women & $26.2 \%=y_{7}$ & $28=t_{1,7}$ & $22.2 \%$ & $19.7 \%$ & $44=t_{2,7}$ & $34.9 \%$ \\
\hline men + women & $20.8 \%=Z_{7}$ & $84=t_{1,7}$ & $8.8 \%$ & $18.7 \%$ & $93=\mathrm{t}_{2,7}$ & $31.7 \%$ \\
\hline Men & $3.4 \%$ & 10 & $31.3 \%$ & $2.2 \%$ & 6 & $18.7 \%$ \\
\hline $\mathrm{i}=8$ women & $12.1 \%$ & 13 & $59.1 \%$ & $2.2 \%$ & 5 & $22.7 \%$ \\
\hline men + women & $5.7 \%$ & 23 & $42.6 \%$ & $2.2 \%$ & 11 & $20.4 \%$ \\
\hline Men & $6.4 \%$ & 19 & $26.8 \%$ & $12.7 \%$ & 35 & $49.3 \%$ \\
\hline$i=9$ women & $3.7 \%$ & 4 & $4.4 \%$ & $13.5 \%$ & 30 & $33.0 \%$ \\
\hline men + women & $5.7 \%$ & 23 & $14.2 \%$ & $13.2 \%$ & 65 & $40.1 \%$ \\
\hline Men & $20.9 \%$ & 62 & $51.2 \%$ & $6.5 \%$ & 18 & $14.9 \%$ \\
\hline $\mathrm{i}=10$ women & $1.9 \%$ & 2 & $5.6 \%$ & $5.4 \%$ & 12 & $33.3 \%$ \\
\hline men + women & $15.9 \%$ & 64 & $40.8 \%$ & $6.0 \%$ & 30 & $19.1 \%$ \\
\hline
\end{tabular}

Part 2 of Table 1.

\begin{tabular}{|c|c|c|c|c|c|c|}
\hline Men & $0 \%$ & 0 & $0 \%$ & $2.9 \%$ & 8 & $61.5 \%$ \\
\hline i=11 women & $0.9 \%$ & 1 & $4.3 \%$ & $2.7 \%$ & 6 & $26.1 \%$ \\
\hline men + women & $0.2 \%$ & 1 & $2.8 \%$ & $2.8 \%$ & 14 & $38.9 \%$ \\
\hline Men & $3.0 \%$ & 9 & $20.9 \%$ & $5.1 \%$ & 14 & $32.6 \%$ \\
\hline $\mathrm{i}=12$ women & $0.9 \%$ & 1 & $4.8 \%$ & $2.7 \%$ & 6 & $28.6 \%$ \\
\hline men + women & $2.5 \%$ & 10 & $15.6 \%$ & $4.0 \%$ & 20 & $31.3 \%$ \\
\hline Men & $2.0 \%=X_{13}$ & $6=t_{1,13}$ & $\alpha_{1}=54.5 \%$ & $0.7 \%$ & $2=\mathrm{t}_{2,13}$ & $\alpha_{2}=18.2 \%$ \\
\hline$i=13$ women & $0 \%=y_{13}$ & $0=\mathrm{t}_{1,13}$ & $\beta_{1}=0 \%$ & $0.9 \%$ & $2=t_{2,13}$ & $\beta_{2}=0.67 \%$ \\
\hline \multirow[t]{4}{*}{ men + women } & $1.5 \%=Z_{13}$ & $6=t_{1,13}$ & $\gamma_{1}=42.9 \%$ & $0.8 \%$ & $4=t_{2,13}$ & $\gamma_{2}=28.6 \%$ \\
\hline & \multicolumn{3}{|c|}{$\sum t_{1, i}=296=$ number of noses obtained for men from artworks } & \multicolumn{3}{|c|}{$\sum t_{2,1}=275=$ number of noses photographed for men in Europe } \\
\hline & \multicolumn{3}{|c|}{$\sum \mathrm{t}_{1, \mathrm{i}}=107 \mathrm{i}=1 \ldots 13$ total number from artworks for women } & \multicolumn{3}{|c|}{$\sum \mathrm{t}_{2, \mathrm{i}}=223 \mathrm{i}=1 \ldots 13$ total number for women } \\
\hline & \multicolumn{3}{|c|}{$\sum \mathrm{t}_{1,1}=403=$ total number from artworks for men + women } & \multicolumn{3}{|c|}{$\begin{array}{l}\qquad \mathrm{t}_{2, \mathrm{i}}=498 \\
\text { total number for men + women }\end{array}$} \\
\hline
\end{tabular}

Part 3 of Table 1.

\begin{tabular}{|c|c|c|c|c|c|c|c|}
\hline \multicolumn{3}{|c|}{$\begin{array}{c}\text { Number of noses of certain nose shape i obtained } \\
\text { by photographs taken in Israel }=t_{k, i}=t_{3, i}\end{array}$} & \multicolumn{3}{|c|}{$\begin{array}{l}\text { Number of noses of a certain nose shape i not } \\
\text { clear where photographed }=t_{k, j}=t_{4, i}\end{array}$} & \multicolumn{2}{|c|}{$\begin{array}{l}\text { Total number of noses of a certain nose shape: } \\
\qquad t=t_{1, i}+t_{2, i}+t_{3, i}+t_{4, j}\end{array}$} \\
\hline $48.3 \%=X_{1}$ & $217=\mathrm{t}_{3,1}$ & $\alpha_{3}=67.4 \%$ & $14.8 \%$ & $9=t_{4,1}$ & $\alpha_{4}=2.8 \%$ & $29.8 \%=X_{1}$ & $322=t$ \\
\hline $23.6 \%=y_{1}$ & $83=t_{3,1}$ & $\beta_{3}=67.4 \%$ & $10 \%$ & $3=\mathrm{t}_{4,1}$ & $\beta_{4}=2.8 \%$ & $15.7 \%=y_{1}$ & $112=t$ \\
\hline $37.5 \%=Z_{1}$ & $300=\mathrm{t}_{3,1}$ & $\gamma_{3}=67.4 \%$ & $13.2 \%$ & $12=t_{4,1}$ & $\gamma_{4}=2.8 \%$ & $24.2 \%=Z_{1}$ & $434=t$ \\
\hline $7.8 \%$ & 35 & $44.8 \%$ & $8.2 \%$ & 5 & $6.4 \%$ & $7.2 \%$ & 78 \\
\hline $2.0 \%$ & 7 & $77.8 \%$ & $0 \%$ & 0 & $0 \%$ & $1.3 \%$ & 9 \\
\hline $5.2 \%$ & 42 & $48.3 \%$ & $5.5 \%$ & 5 & $5.7 \%$ & $4.9 \%$ & 87 \\
\hline $9.6 \%$ & 43 & $41 \%$ & $14.8 \%$ & 9 & $8.6 \%$ & $9.7 \%$ & 105 \\
\hline $10.8 \%$ & 38 & $60.4 \%$ & $16.7 \%$ & 5 & $7.9 \%$ & $8.8 \%$ & 63 \\
\hline $10.1 \%$ & 81 & $48.2 \%$ & $15.4 \%$ & 14 & $8.3 \%$ & $9.4 \%$ & 168 \\
\hline $0 \%$ & 0 & $0 \%$ & $1.6 \%$ & 1 & $16.7 \%$ & $0.6 \%$ & 6 \\
\hline $0.3 \%$ & 1 & $50 \%$ & $0 \%$ & 0 & $0 \%$ & $0.3 \%$ & 2 \\
\hline $0.1 \%$ & 1 & $12.5 \%$ & $1.1 \%$ & 1 & $12.5 \%$ & $0.45 \%$ & 8 \\
\hline $2.0 \%$ & 9 & $11.5 \%$ & $9.8 \%$ & 6 & $7.7 \%$ & $7.2 \%$ & 78 \\
\hline $12.5 \%$ & 44 & $28.6 \%$ & $23.3 \%$ & 7 & $4.5 \%$ & $21.6 \%$ & 154 \\
\hline $6.6 \%$ & 53 & $22.9 \%$ & $14.3 \%$ & 13 & $5.6 \%$ & $12.9 \%$ & 232 \\
\hline
\end{tabular}




\begin{tabular}{|c|c|c|c|c|c|c|c|}
\hline $2.7 \%$ & 12 & $35.3 \%$ & $0 \%$ & 0 & $0 \%$ & $3.1 \%$ & 34 \\
\hline $7.1 \%$ & 25 & $50 \%$ & $3.3 \%$ & 1 & $2 \%$ & $7.0 \%$ & 50 \\
\hline $4.6 \%$ & 37 & $44 \%$ & $1.1 \%$ & 1 & $1.2 \%$ & $4.7 \%$ & 84 \\
\hline $10.5 \%=X_{7}$ & $47=t_{3,7}$ & $28.1 \%$ & $24.6 \%$ & $15=t_{4,7}$ & $9.0 \%$ & $15.4 \%=X_{7}$ & $167=\mathrm{t}$ \\
\hline $13.1 \%=y_{7}$ & $46=t_{3,7}$ & $36.6 \%$ & $26.7 \%$ & $8=t_{4,7}$ & $6.3 \%$ & $17.7 \%=Y_{7}$ & $126=t$ \\
\hline $11.6 \%=Z_{7}$ & $93=t_{3,7}$ & $31.7 \%$ & $25.3 \%$ & $23=t_{4,7}$ & $7.8 \%$ & $16.3 \%=Z_{7}$ & $293=t$ \\
\hline $2.7 \%$ & 12 & $37.5 \%$ & $6.6 \%$ & 4 & $12.5 \%$ & $3.0 \%$ & 32 \\
\hline $1.1 \%$ & 4 & $18.2 \%$ & $0 \%$ & 0 & $0 \%$ & $3.1 \%$ & 22 \\
\hline $2.0 \%$ & 16 & $29.6 \%$ & $4.4 \%$ & 4 & $7.4 \%$ & $3.0 \%$ & 54 \\
\hline $3.6 \%$ & 16 & $22.5 \%$ & $1.6 \%$ & 1 & $1.4 \%$ & $6.6 \%$ & 71 \\
\hline $15.3 \%$ & 54 & $59.3 \%$ & $10 \%$ & 3 & $3.3 \%$ & $12.8 \%$ & 91 \\
\hline $8.7 \%$ & 70 & $43.2 \%$ & $4.4 \%$ & 4 & $2.5 \%$ & $9.0 \%$ & 162 \\
\hline $5.4 \%$ & 19 & $52.8 \%$ & $10 \%$ & 3 & $8.3 \%$ & $5.1 \%$ & 36 \\
\hline $6.7 \%$ & 54 & $34.4 \%$ & $9.9 \%$ & 9 & $5.7 \%$ & $8.8 \%$ & 157 \\
\hline
\end{tabular}

Part 4 of Table 1.

\begin{tabular}{|c|c|c|c|c|c|c|c|}
\hline $0.9 \%$ & 4 & $30.8 \%$ & $1.6 \%$ & 1 & $7.7 \%$ & $1.2 \%$ & 13 \\
\hline $4.5 \%$ & 16 & $69.6 \%$ & $0 \%$ & 0 & $0 \%$ & $3.2 \%$ & 23 \\
\hline $2.5 \%$ & 20 & $55.6 \%$ & $1.1 \%$ & 1 & $2.8 \%$ & $2.0 \%$ & 36 \\
\hline $3.8 \%$ & 17 & $39.5 \%$ & $4.9 \%$ & 3 & $7.0 \%$ & $4.0 \%$ & 43 \\
\hline $4.0 \%$ & 14 & $66.6 \%$ & $0 \%$ & 0 & $0 \%$ & $2.9 \%$ & 21 \\
\hline $3.9 \%$ & 31 & $48.4 \%$ & $3.3 \%$ & 3 & $4.7 \%$ & $3.6 \%$ & 64 \\
\hline $0.4 \%=\mathrm{X}_{13}$ & $2=t_{3,13}$ & $\alpha_{3}=18.2 \%$ & $1.6 \%$ & $1=\mathrm{t}_{4,13}$ & $\alpha_{4}=9.1 \%$ & $1.0 \%=X_{13}$ & $11=t$ \\
\hline $0.3 \%=y_{13}$ & $1=t_{3,13}$ & $\beta_{3}=0.33 \%$ & $0 \%$ & $0=\mathrm{t}_{4,13}$ & $\beta_{4}=0 \%$ & $0.4 \%=y_{13}$ & $3=t$ \\
\hline $0.4 \%=Z_{13}$ & $3=t_{3,13}$ & $\gamma_{3}=21.4 \%$ & $1.1 \%$ & $1=t_{4,13}$ & $\gamma_{4}=7.1 \%$ & $0.8 \%=Z_{13}$ & $14=t$ \\
\hline \multicolumn{3}{|c|}{$\begin{array}{c}\begin{array}{c}\sum \mathrm{t}_{3, \mathrm{i}}=449=\text { total number of noses photographed for men } \\
\text { in Israel }\end{array}\end{array}$} & \multicolumn{3}{|c|}{$\sum \mathrm{t}_{4, \mathrm{i}}=61=$ total number of noses photographed for men } & \multicolumn{2}{|c|}{$\sum \mathrm{t}=1081=$ total number of noses for men } \\
\hline \multicolumn{3}{|c|}{$\sum \mathrm{t}_{3, \mathrm{i}}=352 \mathrm{i}=1 \ldots 13$ total number for women } & \multicolumn{3}{|c|}{$\sum \mathrm{t}_{4, \mathrm{i}}=30 \mathrm{i}=1 \ldots 13$ total number for women } & \multicolumn{2}{|c|}{$\sum \mathrm{t}=712=$ total number for women } \\
\hline \multicolumn{3}{|c|}{$\sum \mathrm{t}_{3, \mathrm{i}}=801=$ total number for men + women } & \multicolumn{3}{|c|}{$\sum \mathrm{t}_{4, \mathrm{i}}=91=$ total number for men + women } & \multicolumn{2}{|c|}{$\sum \mathrm{t}=1793=$ total number for men + women } \\
\hline
\end{tabular}

\section{Part 5 of table 1.}

\section{Effect of nose shape:}

$X_{i}=[($ number of noses for a certain nose shape for men) $/$ (total number of noses for a certain nose shape for men) $] \times 100=$

$\left(\mathrm{t}_{\mathrm{k}, \mathrm{i}} /\left[\mathrm{t}_{\mathrm{k}, 1}+\mathrm{t}_{\mathrm{k}, 2}+\mathrm{t}_{\mathrm{k}, 3}+\ldots .+\mathrm{t}_{\mathrm{k}, 13}\right]\right) 100 \mathrm{k}=1,2,3,4$ where $\sum\left(\mathrm{X}_{\mathrm{i}}\right)=100 \% \mathrm{i}=1,2,3, \ldots \ldots 13$

$Y_{i}=[($ number of noses for a certain nose shape for women $) /($ total number of noses for a certain nose shape for women) $] \times 100=$

$\left(\mathrm{t}_{\mathrm{k}, \mathrm{i}} /\left[\mathrm{t}_{\mathrm{k}, 1}+\mathrm{t}_{\mathrm{k}, 2}+\mathrm{t}_{\mathrm{k}, 3}+\ldots .+\mathrm{t}_{\mathrm{k}, 13}\right]\right) 100 \mathrm{k}=1,2,3,4$ where $\sum\left(\mathrm{Y}_{\mathrm{i}}\right)=100 \% \mathrm{i}=1,2,3, \ldots . .13$

$Z_{i}=[($ number of noses for a certain nose shape for men + women $) /($ total number of noses for a certain nose shape for me + women $)] \times 100=$

$\left(\mathrm{t}_{\mathrm{k}, \mathrm{i}} /\left[\mathrm{t}_{\mathrm{k}, 1}+\mathrm{t}_{\mathrm{k}, 2}+\mathrm{t}_{\mathrm{k}, 3}+\ldots+\mathrm{t}_{\mathrm{k}, 13}\right]\right) 100 \mathrm{k}=1,2,3,4$ where $\sum\left(\mathrm{Z}_{\mathrm{i}}\right)=100 \% \mathrm{i}=1,2,3, \ldots . .13$

\section{Effect of photographing place:}

$\alpha_{j}=[($ number of noses for a certain nose shape for men) $/$ (total number of noses for a certain nose shape for men) $] \times 100=$

$\left(t_{k, j} /\left[t_{1, j}+t_{2, j}+t_{3, j}+t_{4, j}\right) 100\right.$ where $j=1, \ldots ., 13$ and $\left(\alpha_{1}+\alpha_{2}+\alpha_{3}+\alpha_{4}\right)=100 \%$

$\beta_{j}=[($ number of noses for a certain nose shape for women $) /($ total number of noses for a certain nose shape for women) $] \times 100=$

$\left(t_{k, j} /\left[t_{1, j}+t_{2, j}+t_{3, j}+t_{4, j}\right]\right) 100$ where $j=1, \ldots ., 13$ and $\left(\beta_{1}+\beta_{2}+\beta_{3}+\beta_{4}\right)=100 \%$

$\gamma_{j}=[($ number of noses for a certain nose shape for men + women $) /($ total number of noses for a certain nose shape for men + women) $] \times 100=$

$\left(t_{k, j} /\left[t_{1, j}+t_{2, j}+t_{3, j}+t_{4, j}\right]\right) 100$ where $j=1, \ldots, 13$ and $\left(\gamma_{1}+\gamma_{2}+\gamma_{3}+\gamma_{4}\right)=100 \%$ 
The major results and conclusions may be summarized as follows:

(1) Not all real nose shapes in Figure 2 can be identified with those in Figure 1.

(2) The most widespread nose for men and women is shape $1(\mathrm{i}=1)$, $24.2 \%$, the fleshy nose in Figure 2 where the less widespread nose is shape $4(\mathrm{i}=4), 0.45 \%$, turned-up nose. Shape 14 in Figure 2 is the only existing one.

(3) In Israel, for men and women, the most widespread nose is the shape $1(\mathrm{i}=1), 37.5 \%$, the fleshy nose where in Europe it is shape 5 $(i=5), 22.1 \%$, the celestial nose.

(4) The most attractive nose shape is probably the celestial or snub, number 5 and 6 in Figure 2.

A comparison between noses existing in Israel and in Europe in Table 1 yields the following

\section{Conclusion}

a. The percentage of nose shape 1 for men + women in Israel is significantly larger than in Europe, $37.5 \%$ by comparison to $13.5 \%$.

b. The percentage of shape 7 for men + women is larger in Europe than in Israel, $18.7 \%$ by comparison to $11.6 \%$.

c. The percentage of nose shape 13 in Europe and Israel is negligible, $0.8 \%$ and $0.4 \%$. The Former President Richard M. Nixon demonstrates it. d. The percentage of nose shape 4 for men + women are negligible in all cases: $0.7 \%, 0.6 \%$ and $0.1 \%$.

e. The percentage of nose shape 7 in artworks is the highest, $20.8 \%$. It is apparently the most beautiful nose.

In conclusion the author believes that the noses shapes in Figure 2 based on analysis of 1793 noses as well as the analysis of the results in Table 1 gives more precise information about the reality which might enhance a more concentrated analysis and research of what the Nose shape \& Size reveals in our face.

\section{References}

1. http://www.commoncold.org/undrstnd.htm

2. http://en.citizendium.org/wiki/Nose

3. Chi An Kuei. Face Reading. 1998; M. Evans and Company, Inc., NY, USA.

4. http://www.statemaster.com/encyclopedia/Ethmoid-bone

5. http://www.wikidoc.org/index.php/Human_nose

6. Derek, Julia Parker. Face Facts (in Hebrew). 1998; Kinneret Publishing House, Israel.

7. Lailan Young. The Naked Face - The essential Guide to Reading Faces. 1993; St. Martin' Press.

8. Paul E. Keller, Lars J. Kangas, Lars H. Liden, Sherif Hashem, Richard T. Kouzes. Electronic Noses and Their Applications. 1995; In: IEEE Northon/ Technical Application Conference in Portland, OR, USA. 